\title{
Transnational Power Grid Interconnection Potential Evaluation Model and Empirical Research
}

\author{
Lin Liu* ${ }^{*}$, Ning Zhang, Yongfang Jian \\ State Grid Energy Research Institute CO., LTD, Changping, Beijing 102209, P.R.China
}

\begin{abstract}
The paper sets up the two-tier screening evaluation model of potential of transnational grid interconnection that includes the mutual complementation potential model and environmental evaluation model. This two-tier screening evaluation model introduces quantitative index and applies it to the full coverage analysis and calculation of the countries along the "Belt and Road". The combination of qualitative and quantitative analysis forms a complete evaluation system from interconnection potential calculation to electricity investment environment. The empirical analysis demonstrates the effectiveness of two-tier screening evaluation model where the analysis result may serve as the scientific reference of promoting grid interconnection of the countries along the "Belt and Road".
\end{abstract}

\section{Introduction}

For the purposes of implementing the "Belt and Road" Initiative, building the power transmission corridor of Silk Road Economic Belt and further securing the power transmission projects in place, it is necessary to conduct research on the grid interconnection potential of relevant countries[1-3]. The paper firstly probes into the major influencing factors of potential of cross-border grid interconnection and on the basis of which establishes a two-tier screening evaluation model of grid interconnection potential of the countries along the "Belt and Road" including the mutual complementation potential model and environmental evaluation model. This two-dimensional screening evaluation model combines qualitative and quantitative analysis, follows the general thoughts of screening by layer and from macro to micro scale, and covers mutual complementation potential calculation and investment environment analysis, which can serve as scientific reference to the transnational grid interconnection of the countries along the "Belt and Road".

\section{Two-tier screening evaluation model of transitional grid interconnection potential}

The paper establishes the two-tier screening evaluation model of grid interconnection potential of the countries along the "Belt and Road" and the two tiers include the mutual complementation potential model, environment evaluation model and economy evaluation model. This two-tier analysis model combines qualitative and quantitative analysis, follows the general thoughts of screening by layer and from macro to micro scale, and covers the whole process from mutual complementation potential calculation, investment environment analysis to project cost efficiency evaluation, which can serve as scientific reference to the companies engaged in transnational grid interconnection along the "Belt and Road".

The overall calculation process of two-tier screening evaluation model is:

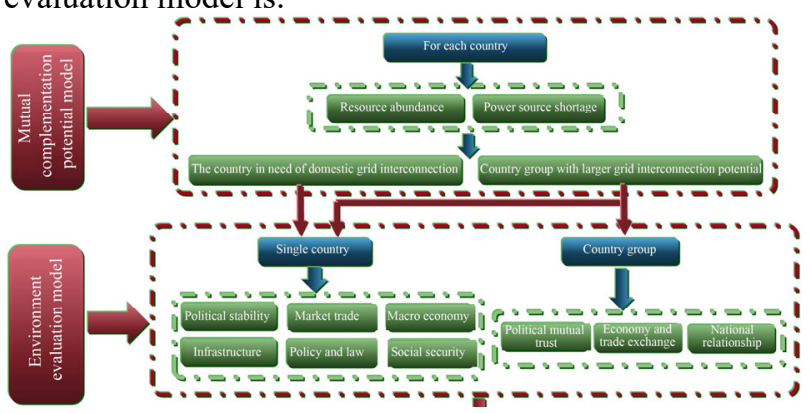

Fig. 1. Two-tier Screening Evaluation Model of Grid Interconnection Potential of Countries Along the "Belt and Road"

(1) The mutual complementation potential model generates the groups of transnational grid interconnection, quantifies and calculates and interconnection mutual complementation coefficients, and screens out the groups of higher coefficients as the candidate bilateral and trilateral grid interconnection groups of larger potential.

(2) The environment evaluation model works out the evaluation result of electricity investment environment of any single country as well as the correction coefficients of bilateral and trilateral relations[4-6]; by overall consideration of the transnational grid interconnection groups selected by the mutual complementation potential model and the environmental

\footnotetext{
* Corresponding author: liulinmu@163.com
} 
evaluation result of the corresponding countries in the environment evaluation model, the joint calculation result of mutual complementation potentialenvironment evaluation serves as the final result of transnational grid interconnection potential evaluation.

\subsection{Mutual complementation potential model}

The general idea of mutual complementation potential model is to conduct all-covering analysis and calculation of major countries from the perspectives of resource abundance and electricity sufficiency, label the results in a two-dimensional plan, consider the neighboring relations of geographic locations of countries and their quadrants and locations in the plan, measure the mutual complementation potential of neighboring countries and form the interconnection groups of two, three or even more countries. The result of quantitative evaluation shows the relative potential level of mutual complementation.

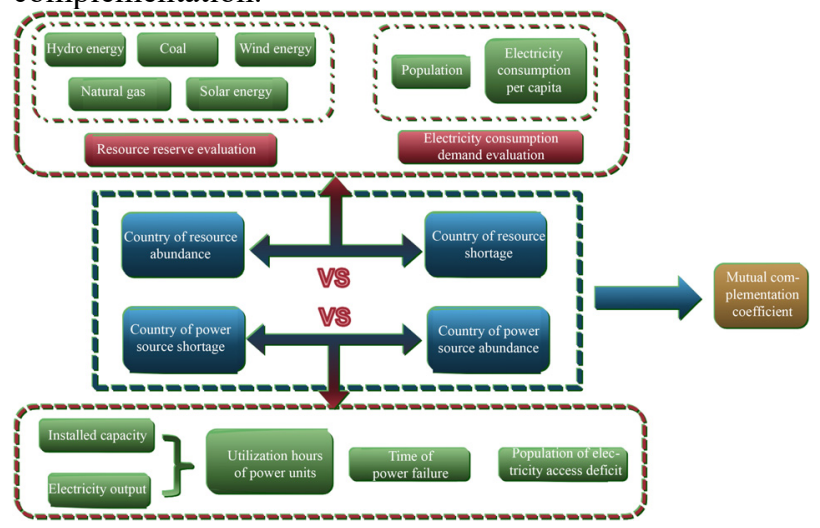

Fig. 2. Transnational Mutual Complementation Potential Analysis Model

Below are the relevant system indices:

(1) Resource abundance

(1) Evaluation of conventional energy reserves

The data of conventional energy reserves like coal, petroleum, natural gas, hydro energy, etc. of 200 countries are collected and as per the data of typical power generation efficiency are converted into potential electricity output.

(2) Evaluation of new energy resource-solar energy

By input of the longitudes and latitudes of major cities of 200 countries and regions, the iMAP software on web of SOLARGIS provides the total horizontal radiation intensity; multiply the radiation intensity with the corresponding territory area and then multiply the solar-to-electricity conversion rate for the potential output of solar power of the intended country or region.

(3) Evaluation of new energy resource - wind energy

Based on the global wind velocity statistics (including the monthly wind velocity data of each point of longitude and latitude) available on ESRL web and the territory area of each country, the wind energy reserves of 200 countries and regions are evaluated.

(4) Electricity consumption demand

Based on the population and electricity consumption per capita of each country or region released by World
Bank, the annual electricity consumption is calculated to reflect its annual consumption demand.

Given the aforesaid four indices, the total resource reserve of each country is worked out by weighting of general consideration of the traditional energy and new energy reserves, its energy transition result and the present technology level of solar and wind energy development.

Supposing the total resource reserve of $I_{a}$ and electricity demand of $I_{b}$, the resource abundance $I_{y}$ is:

$$
I_{y}=\frac{\varphi\left(I_{a}-I_{b}\right)+\varphi\left(I_{a} / I_{b}\right)}{2}
$$

$\varphi$ is normalization of values within $(-1,1)$.

(2) Electricity abundance

Based on the statistics of installed capacity and power output of over 200 countries and regions available at BloombergNEF web, the power unit utilization hours of the relevant countries and regions are calculated and by reference to the parameters like proportion of population with electricity access, outage time, electricity import and export ratio, etc. the electricity abundance of these countries and regions is evaluated by weighting.

Supposing the power unit utilization hours is $I_{c}$, the proportion of population with electricity access is $I_{d}$, the electric energy quality is $I_{e}$ and the electricity import and export ratio is $I_{f}$, the values of two coordinate axes are calculated by the following formula.

The electricity abundance $I_{x}$ is:

$$
I_{x}=\varphi\left(r_{c} I_{c}+r_{d} I_{d}+r_{e} I_{e}+r_{f} I_{f}\right)
$$

Where: $r$ is the weighting coefficient.

Hence the electricity abundance $I_{x}$ and resource abundance $I_{y}$ of each country are shown in the 2D coordinate plan in Figure 3.

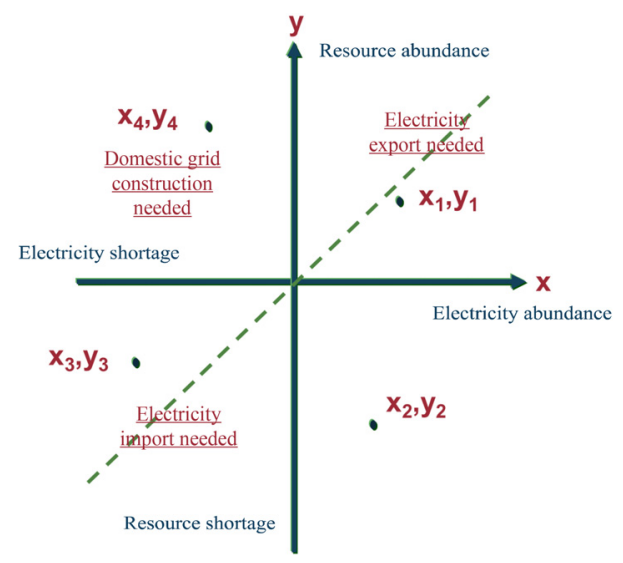

Fig. 3. Sketch of Transnational Mutual Complementation Potential Analysis

Given the above figure, the "mutual complementation coefficient" is defined as the tangential component of the section connecting two or more coordinate points of country along the $y=x$ line; for the neighboring countries, the higher mutual complementation coefficient means larder potential of grid interconnection. 


\subsection{Environment evaluation model}

The general ideas of environment evaluation model are to sort out and summarize the worldwide research institutes' research efforts on credit and risk by country, consider the development demand of electricity interconnection of the countries along the "Belt and Road", set up an evaluation system by selection of the pertinent index, and a evaluation model of electricity investment environment by country so as to figure out the evaluation result of the electricity investment environment of each country.

The system of electricity investment environment evaluation by country makes general analysis of numerous indices contained in Doing Business, International Country Risk Guide, Global Enabling Trade Report, World Energy Trilemma Index, Global Competitiveness Report, World Economic Outlook, Country Risk Rating and Human Development Report, and in line with the project context designs the comprehensive index system of electricity investment environment by country[7-10].

The country electricity investment environment evaluation model includes 6 first-class indices and 50 second-class indices.

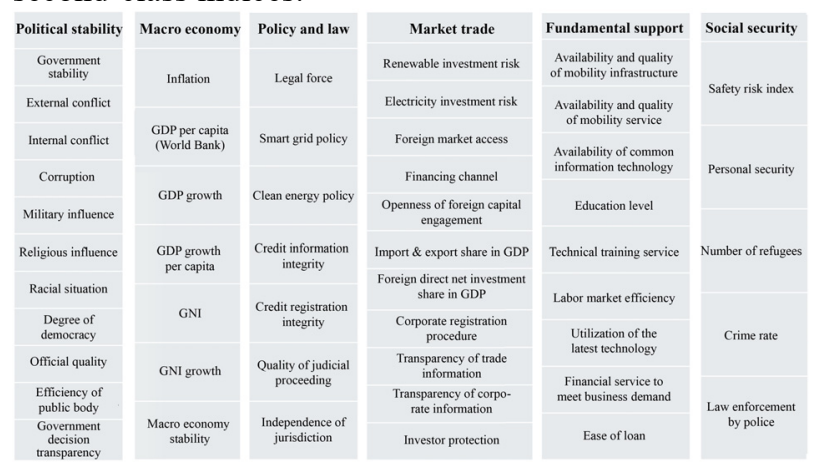

Fig. 4. Country Electricity Investment Environment Evaluation Model

\section{Empirical Research}

The empirical analysis of the countries along the "Belt and Road" demonstrates the effectiveness of the abovementioned two-tier screening evaluation model.

\subsection{Results of mutual complementation potential calculation}

Based on the mutual complementation potential model, the electricity abundance $I_{x}$ and resource abundance $I_{y}$ are calculated.

The transnational mutual complementation coefficients are calculated including bilateral interconnection and trilateral interconnection coefficients, and the groups with higher coefficients are screened out. See Figure 5 and 6.

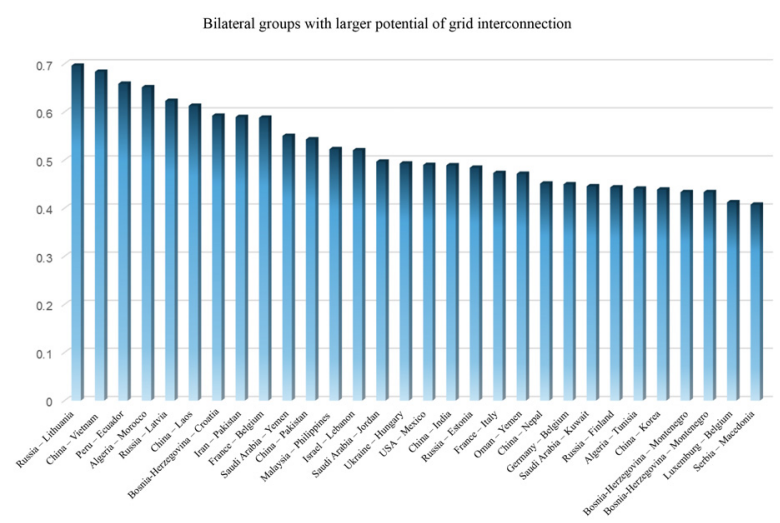

Fig. 5. Result of Mutual Complementation Coefficient Analysis of Bilateral Grid Interconnection

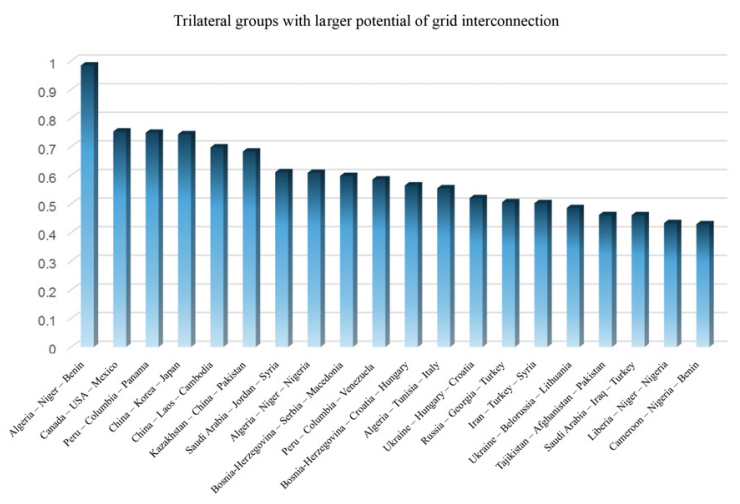

Fig. 6. Result of Mutual Complementation Coefficient Analysis of Trilateral Grid Interconnection

\subsection{Calculation results of environment evaluation}

(1) Results of electricity investment environment evaluation by country

More than 200 countries are involved in the evaluation and the top and bottom 20 countries are respectively:

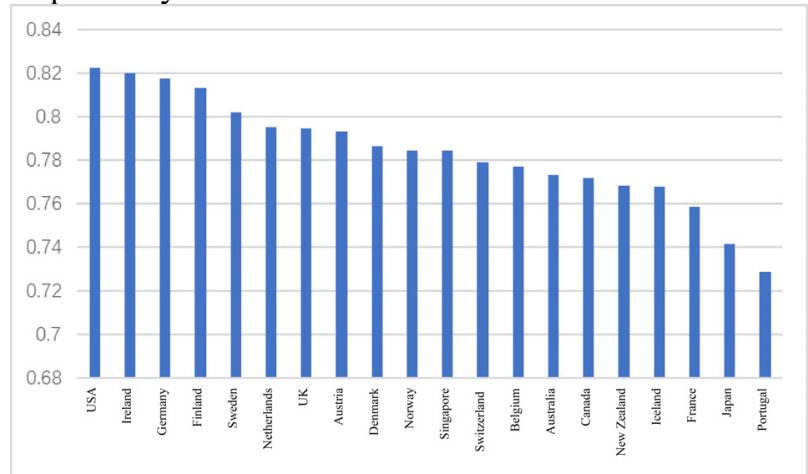

Fig. 7. Top 20 Countries in Electricity Investment Environment Evaluation

\subsection{Comprehensive calculation results}

Based on the country groups of grid interconnection screened by the mutual complementation potential model, 
the results of electricity investment environment evaluation are multiplied with weighted correction to get the following results:

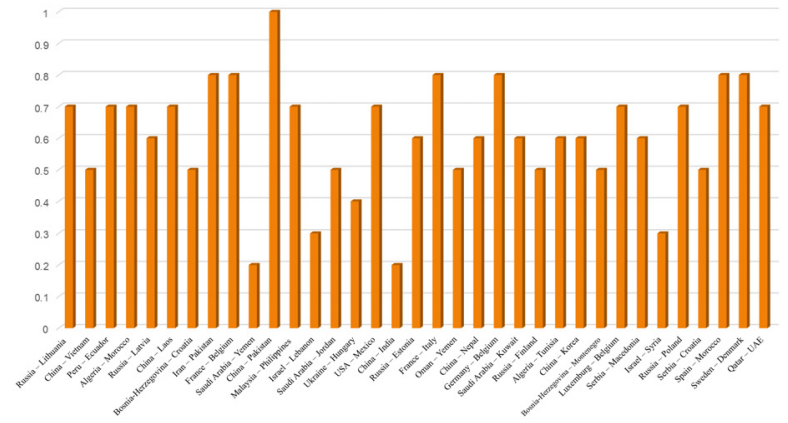

Fig. 8. Calculation Results of Correction Coefficient Applied to Bilateral Relation Groups

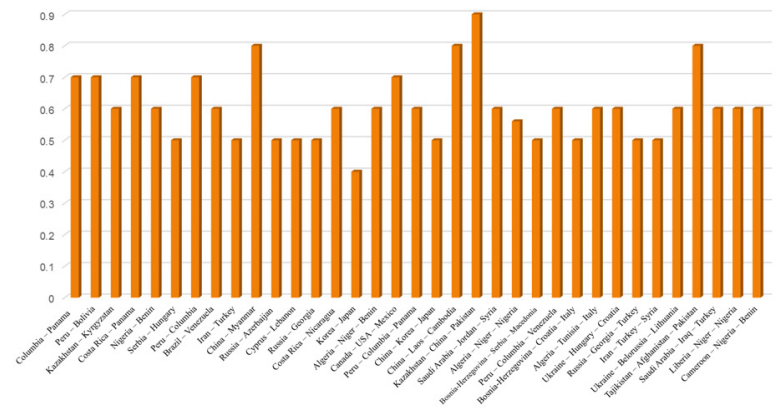

Fig. 9. Calculation Results of Correction Coefficient Applied to Bilateral Relation Groups (continued)

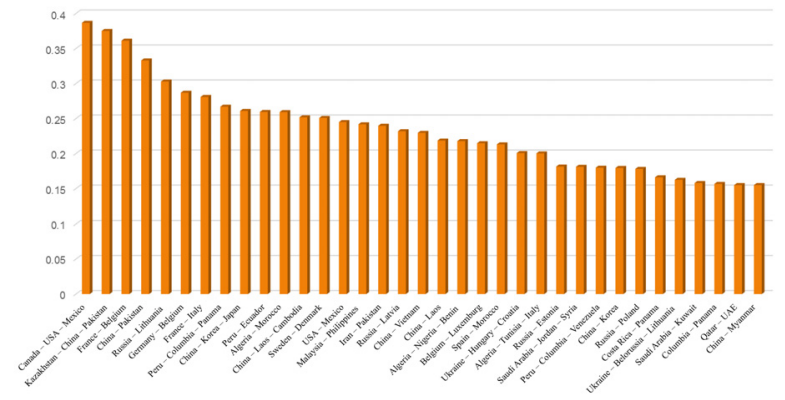

Fig. 10. Comprehensive Calculation Results of Environment Evaluation of Transnational Grid Interconnection Groups

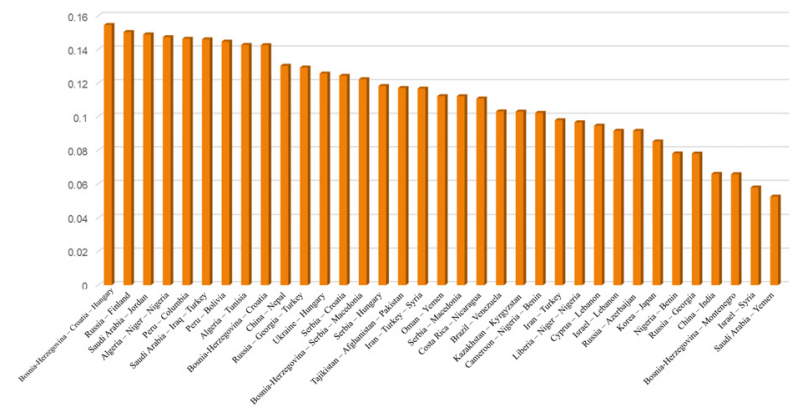

Fig. 11. Comprehensive Calculation Results of Environment Evaluation of Transnational Grid Interconnection Groups (continued)

The bilateral and trilateral grid interconnection calculation results of the mutual complementation potential model and environment evaluation model are generally considered to get the country groups of the largest grid interconnection potential as below:

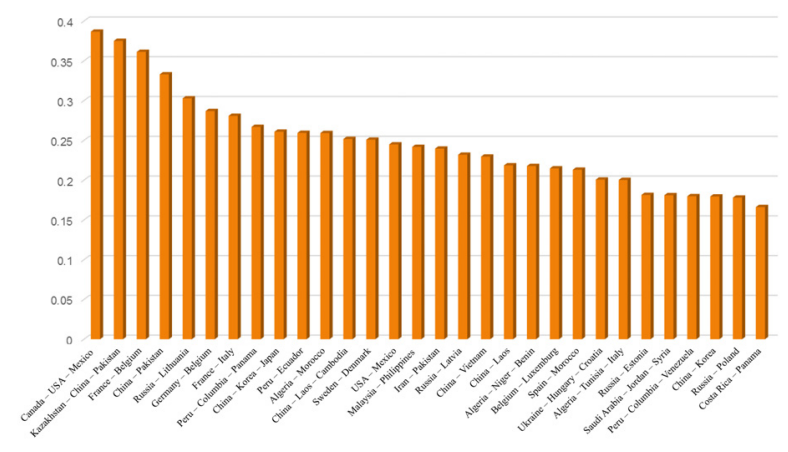

Fig. 12. Joint Calculation Results of Grid Interconnection Potential and Environment Evaluation of Transnational Groups

\section{Conclusions}

The paper establishes a two-tier screening evaluation model for the grid interconnection potential of the countries along the "Belt and Road" and its calculation results are consistent with the presently focused electricity interconnection cooperation projects that demonstrate the strong practicability and application value of model. The mutual complementation potential analysis model can be applied to guide the future planning of power transmission lines and networks. The potential transnational combinations of candidate countries can be selected. The evaluation results of electricity investment environment of the countries along the "Belt and Road" can be guidances of power investment.

\section{Acknowledgement}

Supported by the research project 'Research on Global Power Interconnection, Economic and Social Investigation and Trend'(GEIC-E[2017]060)

\section{References}

1. F.Liu, C. Chen, WEP, 5, 18 (2011)

2. C. Ma, G. Wei, L.Zhang, QIP, 38, 31 (2014)

3. Q. Xu, L. Cai, X. Liu, IPE, 25, 11(2017)

4. WBG, Doing Business, Comparing Business Regulation for Domestic Firms in 190 Economies, (2017)

5. BMI, Country Risk Index Report, 3, 20 (2017)

6. UNDP, Human Development Report, 4, 25 (2016)

7. WEC, World Energy Trilemma Index, 5, 103 (2016)

8. WEF, The Global Enabling Trade Report, 2, 25 (2016)

9. WB, World Development Indicators, 6, 86 (2017)

10. WB, Global Financial Development Report, 7, 130(2016) 